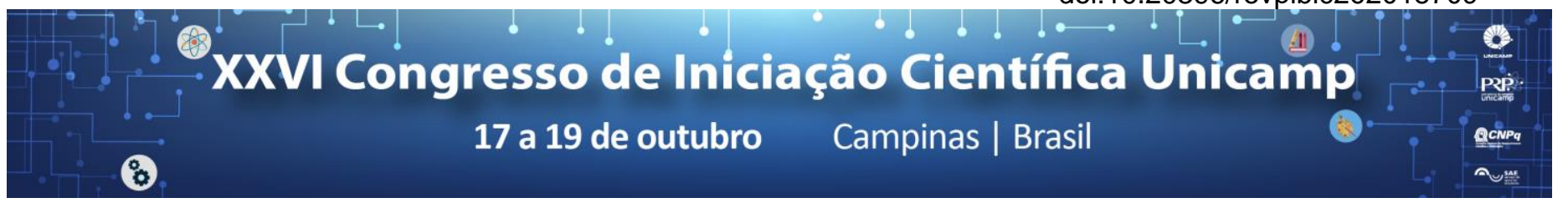

\title{
Impressão em 3D de Circuitos Eletrônicos Flexíveis baseados em Grafeno
}

\section{Julia F. A. Alves*, Gabriel T. Callado, Juliana B. Carvalho, Cristiano M. B. Cordeiro, Ana Luiza C. Pereira}

\begin{abstract}
Resumo
Neste trabalho foram utilizadas técnicas de manufatura aditiva (impressão 3D) para realizar a impressão de circuitos eletrônicos flexíveis a partir de filamento nanocompósito condutivo, de PLA e grafeno. Foram estudadas propriedades de condução de trilhas e circuitos impressos sobre folha de transparência, investigando-se a dependência da resistência elétrica destes com diferentes parâmetros de impressão e com a temperatura. Verificou-se que o material impresso é condutor e ôhmico para todo o intervalo de temperaturas investigado e que os circuitos funcionam bem e mantêm boa aderência à base, mesmo quando sujeitos a curvaturas consideráveis.
\end{abstract}

\section{Palavras-chave:}

Impressão 3D, Grafeno, Circuitos eletrônicos flexíveis

\section{Introdução}

Atualmente tem havido um enorme interesse em estudos envolvendo impressão 3D usando filamentos condutores baseados em grafeno, visando especialmente aplicações relacionadas a dispositivos eletrônicos e energia ${ }^{1,2}$. O grafeno é um material bidimensional, cuja descoberta em 2004 rendeu o prêmio Nobel de Física, e que apresenta propriedades excepcionais de condutividade ${ }^{3}$. A adição de grafeno a nanocompósitos poliméricos para produção de filamentos permite aumentar drasticamente a condução elétrica das peças impressas.

O projeto envolveu projetar e produzir um circuito eletrônico flexível utilizando técnicas de impressão 3D a partir de um filamento condutor à base de grafeno, caracterizando suas propriedades condutoras.

\section{Resultados e Discussão}

O filamento utilizado neste trabalho é à base de grafeno e PLA (ácido polilático), adquirido da empresa Graphene 3D Lab4. Em uma impressora 3D (Sethi3D AiP), trilhas foram impressas variando-se os parâmetros de largura $(2,0$ a $4,0 \mathrm{~mm})$, preenchimento $(10 \%$ a $90 \%)$, e espessura $(0,15$ a $0,30 \mathrm{~mm})$. Medidas de resistência elétrica para os diferentes parâmetros foram obtidas tanto com um multímetro, quanto com o método de medida de quatro pontas. A resistência diminui conforme aumenta-se a espessura e/ou a largura da trilha impressa, conforme esperado. As resistividades determinadas ficaram em torno de $12 \Omega \mathrm{mm}$, variando entre 9,0 e $15,0 \Omega \mathrm{mm}$.

Os gráficos IxV obtidos nas medidas de quatro pontas mostraram-se sempre lineares (material ôhmico), para diferentes temperaturas. A resistência elétrica apresenta ligeiro aumento com a temperatura, no intervalo avaliado de 20 a $80^{\circ} \mathrm{C}$, indicando comportamento condutor para as impressões a partir deste nanocompósito.

$\mathrm{Na}$ figura 1 mostramos dois dos circuitos eletrônicos flexíveis impressos, com LEDs, demonstrando seu funcionamento mesmo sob curvatura considerável. Os circuitos são alimentados por uma bateria e foram projetados para que o acendimento dos LEDs, com diferentes intensidades, indiquem as diferentes resistências das trilhas impressas. A resistência é controlada pela espessura da impressão: as trilhas correspondentes aos LEDs mais à esquerda são mais espessas (menores resistências) nestes casos.
Figura 1. Circuitos Flexíveis Impressos em 3D.
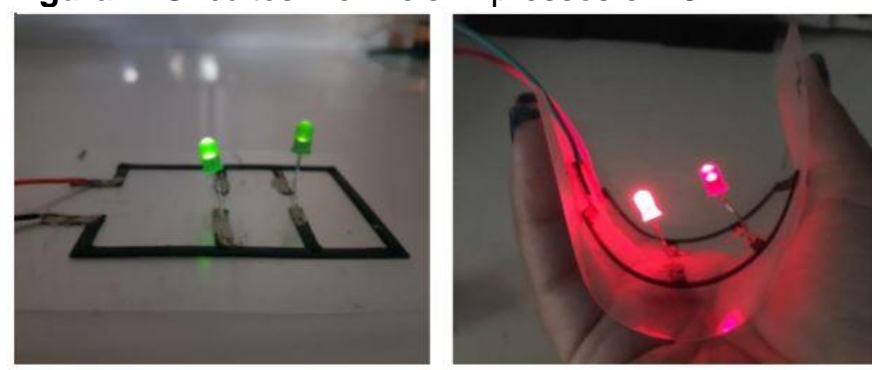

\section{Conclusões}

A impressão 3D a partir de filamentos condutores abre caminho para diversas aplicações, e o estudo realizado deixou em evidência a facilidade e flexibilidade de produção que esse processo proporciona. Alterando-se apenas as espessuras das diferentes trilhas impressas, foi possível imprimir um circuito eletrônico e, usando LEDs, comprovar as diferentes resistências, demonstrando seu funcionamento, flexibilidade e boa adesão à base (transparência).

Grande interesse tem havido nesses circuitos a partir de impressões 3D com os filamentos condutores à base de grafeno para aplicações no desenvolvimento de dispositivos eletrônicos flexíveis e em especial para sensores. Através da sensibilidade em medidas de resistência elétrica neste tipo de circuito com variações no meio, têm sido propostos sensores mecânicos (que detectam variações nas forças de compressão, tração, torção e flexão); sensores de temperatura (nos quais mudanças de temperatura estão relacionadas à mudança na resistência, como verificamos neste trabalho) e sensores de gases (ao entrar em contato com alguns gases, o material apresenta mudanças na resistência, com aplicações na área ambiental, química, biológica ${ }^{5,6}$.

\footnotetext{
1 D. Zhang et al., "Fabrication of highly conductive grapheme flexible circuits by $3 D$ printing" Synthetic Metals 217,79 (2016)

${ }^{2} \mathrm{~K}$. Fu et al., "Progress in 3D printing of Carbon Materials for EnergyRelated Applications" Advanced Materials 29, 1603486 (2017)

3 A. K. Geim and K. S. Novoselov, "The rise of graphene", Nature Materials 6, 183 (2007)

4 BlackMagic3D "Conductive Graphene Filament". Graphene 3D Lab

5 T. T. Tung, et al., "Recent Advances in Sensing Applications of Graphene Assemblies and Their Composites", Adv. Funct. Mater., 27, 1702891(2017)

${ }^{6}$ Y.S. Rim et. al,"Recent Progress in Materials and Devices toward Printable and Flexible Sensors". Advanced Materials 28, 4415 (2016)
} 